\title{
Application research of solar energy optoelectronic system in the design of culture square
}

\author{
Qi Feng YAN \\ Bozhou college Anhui,Bozhou 236800
}

\begin{abstract}
In recent years,as people worsen recognition of revival environment and world energy issue,they have started caring about solar energy,which is convenient to achieve,cheap and renewable clean energy,called the 21 century golden energy.Now our project each of designer need worth thinking is how to apply clean and energy-saving solar energy optoelectronic system to square landscape design.To survey and study about solar energy optoelectronic technology in the culture square design has vital influence from the point of economic and social sustainable development and earth ecology.
\end{abstract}

Key words:solar energy optoelectronic system;conventional energy;ecologicalization;culture square design.

\section{Introduction}

As our country is advancing further Reform and opening up policy and rising living standard,people whether in countryside or in city, develop their demand to culture square function from original space to daily multifunction reception room, which presents more demands for design. The culture square design doesn't pursue natural landscape,but also pay more attention to design and construction of human landscape so that we can close nature more, feel more comfortable,enjoy more complete facilities lighting,heating,refrigeration equipment), more environmental materials etc.However,statistical data shows if exploitation quantity of energy in the world remains the present level,petroleum on earth will dry up 42 years later,natural gas and coal will use up 66 years later and 150 years later respectively.Thus, in terms of energy utilization, enough construction of culture square will use up more nonrenewable energy,meanwhile worsen the environment which completely obey our original intention to construct squares.Solar energy is considered as a convenient and

${ }^{a}$ Corresponding author: 1060198680@qq.com clean renewable resource.Project we worth studying is to apply solar energy optoelectronic system to integrated design of cultural square.

\section{Research background and meaning of solar energy optpelectronic technology in square landscape design}

\subsection{Research background}

It is known that developed countries like USA,Japan,Germany,France,Italy are giant countries on energy consumption which get achievement in application technology of solar energy construction .It is French famous heating of thermal storage walls that belongs to invention of French Felix Trombe .Meanwhile,recent years occur zero-consumption house in the world, it is completed with solar energy belonging to energy consumption and it's really clean and pollution-free which represents development trend of the 21 st century solar energy construction.As a giant country 
with great energy consumption,America not only invest lots of expenditure in exploitation and utilization of solar energy, but the government also implements tax reduction for consumers.Thus, in recent years,solar energy gains fast development and application as well as promotion,because it possesses leading position in either its study about use technology of solar energy ,study of design optimization or study about new materials, product development,improvement and promotion of construction parts structure.As it were,now America has formed solar energy construction industry integration.

Our country has a vast territory,possesses abundant solar energy.Except that parts of areas (like Zichuan,Guiyang province) are not fit for utilization,most of our country suitably utilizes solar energy.It is estimated that each year amounts of solar energy radiation inland receives is equal to 240 billion tons standard coals.Annual average radiation amount is up to 5,900 megajoule(MJ)/Sq.Our optoelectronic system 'application research began in the late 1970s, we have experienced constant exploration and practice for 40 years, eventually achieve partial results. The development of solar energy systems equipment has a large number of social practice life, and has gained good social and economic benefits. Therefore, effective application for the system in the cultural square design can not only save a lot of conventional energy, and the prevention and control of environmental pollution has effects that cannot ignore.So we advocate "ecological square design, clean e energy application" .In fact,it is the problem of how to utilize well solar energy system.Certainly, the progress of science and technology, will also increase utilization efficiency of the system, decrease construction cost which expands increasingly and promote its application scope.

\section{2 research meaning}

Square construction is unnecessary process in the modernization city and new-type countryside construction.To study square landscape design application in the solar energy optoelectronic technology has the following three reality meanings: Advocating low-carbon life, improving people' life quality

In recent years, with continuous development of our country's gross national product (GNP), matched lighting, sound, refrigeration, heating and water-consuming system in the square design has become the basic requirement for urban and rural culture square. Culture square construction introduces solar energy optoelectronic system into the lighting facilities, air conditioners, stereos, solar water heaters, air purifiers, water purifiers and so on.It not only saves conventional energy but it is also safe and reliable, healthy and environmental. What's more is a good way to effectively solve the urban and rural culture square construction Promotion.

\subsection{Optimizing energy structure, replacing the conventional energy resource}

Main energy our country is consuming is coal, oil and natural gas.However,conventional energy resources in China are quite limited. the more and more decreasing resource will dry up one day.Therefore, vigorous development for renewable energy sources such as solar photovoltaic resource not only can replace and save conventional energy, but also it is a really feasible sustainable development road.Square landscape design promotes use of solar photovoltaic technology, which not only saves space and excavation engineering, but also will have important significance on controlling the conventional energy consumption, optimizing energy structure.

\section{Characteristic analysis of utilization about china's solar energy photovoltaic resources in square landscape design}

As a kind of new energy, solar energy photoelectricity compares with conventional energy such as fossil fuels (coal, oil, natural gas) and nuclear fuel, it has the following several characteristics:(a) 


\section{1 solar photoelectricity is inexhaustible, inexhaustible}

Each year, according to the existing data,it is estimated that solar energy radiation the Chinese land received is the equivalent of 2.403 trillion tons of standard coal, an annual radiation amount is about 5.9 billion joules per square meter.China has a vast territory,solar energy resources is available, abundant and inexhaustible .For the remote and inconvenient areas like the western China shows its superiority.As long as the one-time investment construction is in place, usual maintenance costs are much smaller compared to the other energy. Of course, in addition to the local area (such as sichuan, guizhou and other places) are not suitable for solar energy utilization, most areas in China is fit for use of solar energy.It is estimated that each year solar radiation amount China inland receives is equal to 2.4 trillion tons of standard coal, an annual radiation amount is about 5.9 billion joules per square meter.

During"five-year" period, our relative research will divide the solar energy resources into five categories areas. The first,second,third type of regions' annual sunshine duration is more than $2000 \mathrm{~h}$, the amount of radiation is higher than $5000 \mathrm{MJ} / \mathrm{m}^{2}$. A is rich solar energy resources, the area is larger, accounting for about two-thirds of the nation's total, which has the good condition of utilizing solar energy. The fourth or fifth class area has worse solar energy resources condition, but still has a certain use value.

Solar energy is the most abundant energy human discovered up to now. The sun constantly happens to nuclear reaction and radiates energy outward,and its quality has a loss.It is estimated that the sun lifetime is about 60 billion years,yet the earth life is about 5 billion years. Therefore, we can say the solar energy is inexhaustible, relative to a few thousand years of civilization of human society and history of human for a shorter time to use fossil fuels, solar energy has more perpetuity.

\subsection{Solar energy is a green, clean energy}

Conventional energy will release a large number of harmful gas in the use ,nuclear fuel will discharge radioactive waste, which can pollute environment.But the use of solar energy can greatly reduce environmental pollution, so the solar energy is clean energy worthy of promoting in the culture square design.

\section{Solar photovoltaic dispersion}

While solar radiation spreads the global,the incident power per unit area is small. So,to get greater efficiency must be required larger lighting area, which will involve the equipment, material, structure, the occupation of land and other cost problems, yet cultural square just can satisfy the above all kinds of related conditions, so the introduction of solar photovoltaic system in the culture square is a very wise choice

IV.The application principle of photovoltaic system in the culture square design Square.

As an important part of public open space, shows as a continuous, holistic, unified streets background,the vision shows the richness of landscape elements, such as trees, fountains, sculpture, seat and modern lighting system, air purification systems, water heating system and so on .Square design is the most typical modern city landscape design.Designing excellent square has strengthened the cohesion of the city itself and external attraction, forms urban public space while construct city guard space against disaster, at the same time, improve the service functions of the city, such as multiple roles.Therefore, plan and design application of solar photovoltaic technology in square landscape design is particularly important to improve the city's image, enhance the attraction of the city .

\section{1 the application principle of "people- oriented"}

The ultimate goal of cultural square design applies arts, science, technology and other means to meet the demand of existence and development in a social setting. The use of city square should fully embody care for people, previous square is small green space without air 
purification system and high-tech lighting system, taking firm ground or construction as the principal thing;Modern plaza appears a large green space, air purification system, high-tech lighting system, water treatment system, audio system, air-conditioning system etc to collocate and transform through the clever solar energy photovoltaic technology facilities,so as to realize the "functionality", "technological" and "environmental protection" of square, strengthen the awareness that cultural square is considered as a public center "living room".Planning design of modern culture square considers "person" as the main body, indicates"human nature ", and it is further close to people's lives.

Square should have enough firm ground to supply people for activities, and shall ensure that not less than $25 \%$ green area,irrigation,weeding and other kinds of security of green land need photovoltaic system to guarantee so that people to relieve summer heat, and enrich color and stratification of landscape level.

Square need have seats, water fountain, public toilets, telephone booth, small kiosks and other service facilities, and also have some sculptures, sketch to enrich the content to make the square have more cultural connotation and artistic appeal.The normal operation need photovoltaic system as guarantee, only make design novel, layout rational and environment beautiful, functions complete, which can fully meet the general public' different needs from high art appreciation to fitness, entertainment and leisure.

Improve the practicability of water space, water landscape form, sound, color are the three elements in the design.Both still water and flowing water will bring the ripples of heart, give a person infinite association.But it needs solar energy photovoltaic system to provide security. Whether it is a man-made waterfall, fountain or not will take passion and satisfies human visual enjoyment.

\section{2 highlighting the design principles of lighting landscape}

The modern people has increasingly rich nightlife,brightening of city square has become a key problem in the construction of city.It is a lighting technology to shape city night scene with lights to beautify the city, show the city individuality, enhance the quality of life, improve the investment environment, promote the development of tourism industry which plays an active role.[3] Only blend deeply solar energy photovoltaic technologyin in the design to adjust mutual relationship suitable to local conditions, integrating various elements inside the space,together with getting good effect.

\section{3 ombining with local light condition,blending reasonably the principle of architecture design concept.}

Firstly, use cultural square solar energy photovoltaic system constructs must consider local illumination factor in the design, because the light in different region and season has a big difference, integrating cultural square solar energy photovoltaic system designs should make full use of sunlight conditions.At the same time, cultural square using solar energy lighting system construction must meet the aesthetic needs for cultural square, but in terms of the current domestic architectural design, above two principles are comprehensively designed into a cultural square which need make great efforts. This needs reasonably arranging relations of design and construction when doing design, but the prospects are good too.

\subsection{Efficiency balance principle}

Significance appears increasingly that modern urban comprehensively utilize square urban space and comprehensively solve the problem of environmental problems.Therefore, planning design of city square have thoughts of "ecology first" humanities and environment coordinating development.Solar energy photovoltaic system as the application of green resources in construction industry is a fairly new concept.In modern society, solar energy resources are mainly used in solar power, solar heating, solar water heaters and solar energy air conditioning and so on. The application of solar 
technology only is confined to smaller areas, and it does not need spend more cost.At the same time, the equipment of the heating system in solar energy photovoltaic system played a key role, so in the culture square design, the process of the use of solar photovoltaic systems need pay equal attention to principle of economic benefit, social benefit and environment benefit .

\subsection{Reasonably using solar energy,realizing principles of energy ecologicalization}

The design of square uses ecological energy and material as far as possible,recycles the materials as far as possible,maximizes the potential of energy and materials.[4] Solar energy photovoltaic system is the most common technical means in the daily life.To this end, when we use it in the cultural plaza design,firstly we should note the solar photovoltaic technology.Only comprehensively consider parameters of the solar energy photovoltaic system, the materials application as well as the various building environment to make the design of solar energy photovoltaic system to do the best.

\section{Conclusion}

In a word, cultural square is leading actor among the urban culture square and the new countryside culture square design, reflecting the diversity of modern urban and rural areas.In addition, the application of solar photovoltaic system is the lifeblood concerning the social and economic development,but the development of traditional energy causes more and more serious crisis problem .Therefore, in the modern cultural square design, we shall consciously strengthen the popularization and application of solar photovoltaic system.As a good designer, we not only require artistry and scientific nature of design works, more attention should be paid to the ecology, energy conservation, create vibrant urban and rural cultural square,so that propose and utilize the square.At the same time, the consciousness of sustainable development should be understood,know new energy technology and application specification as far as possible, in order to advocate and actively use solar photoelectricity and other renewable resources in the design ,eventually design a comfortable, beautiful, green and environmental urban and rural culture square.

These guidelines, written in the style of a submission to MATEC Web of Conferences, explain how to prepare your paper using Microsoft Word.

Please submit sources files directly to the conference organizer. If the conference editors chose to provide print-ready PDF documents to the publisher, you have to submit high-resolution PDF file with all fonts embedded (see PDF guidelines) instead of the sources files. In this case, please remember that no final corrections will be made by the publisher.

Here are some examples:

1. Huang Yicheng. Energy encyclopedia [M]. Beijing: China encyclopedia publishing house, 1997:600-611

2. Gao Feng, Sun chengquan, Liu Quangen. Some ideas about the situation of the exploitation and thoughts about utilization of solar energy in our country [J]. Energy Engineering, 2000 (5) : 8-11.

3. (USA) Kevin lynch, Xiang Bingren. City impression [M]. Beijing: China building industry press, 1990:42-53

4. Chen Lishun, Dai Dashuang. model study about ecological supply of Urban energy [J].Development and economics of science and technology ,the fifth Phrase, 2006:152-153 